\title{
A protein synthesis and nitric oxide-dependent presynaptic enhancement in persistent forms of long-term potentiation
}

\author{
Victoria P.A. Johnstone and Clarke R. Raymond ${ }^{1}$ \\ Department of Neuroscience, The John Curtin School of Medical Research \& Eccles Institute of Neuroscience, \\ The Australian National University, Canberra ACT 0200, Australia
}

\begin{abstract}
Long-term potentiation (LTP) is an important process underlying learning and memory in the brain. At CA3-CA1 synapses in the hippocampus, three discrete forms of LTP (LTP1, 2, and 3) can be differentiated on the basis of maintenance and induction mechanisms. However, the relative roles of pre- and post-synaptic expression mechanisms in LTP1, 2, and 3 are unknown. Neurotransmitter release in the expression of LTPI, 2, and 3 was measured via FM 1-43 destaining from CA3 terminals in hippocampal slices from male Wistar rats (7-8 wk). No difference in vesicle turnover rate was observed for LTP1 up to 160 min following induction by one train of theta-burst stimulation (ITBS). A presynaptic enhancement was found for LTP2 at 160 min after induction by 4TBS, and for LTP3 at both 80 and 160 min after induction by 8TBS. Inhibition of nitric oxide (NO) signaling blocked both LTP2 and LTP3 maintenance and the associated enhanced release. LTP2 maintenance and its presynaptic expression were dependent on protein synthesis, but not gene transcription. LTP3 maintenance was dependent on both translation and transcription, but like LTP2, the enhanced release only required translation. These data considerably strengthen the mechanistic separation of LTP1, 2, and 3, supporting a model of multiple, discrete forms of LTP at CA3-CAl synapses rather than different temporal phases.
\end{abstract}

Long-term potentiation (LTP) in the hippocampus is a model system for investigating the mechanisms of long-term synaptic plasticity and its role in learning and memory in the brain (Bliss and Collingridge 1993; Martin et al. 2000). However, progress in understanding the mechanisms responsible for LTP has been hampered by the existence of multiple LTP variants, even at a single set of synapses. We have recently characterized three discrete forms of LTP at the CA3-CA1 synapse that differ in their persistence, the $\mathrm{Ca}^{2+}$ signals required for their induction, and their electrophysiological requirements (Raymond and Redman 2002, 2006; Raymond 2008). These findings have been incorporated into a model whereby CA3-CA1 synapses support at least three mechanistically and perhaps functionally discrete forms of LTP, termed LTP1, 2, and 3 (Abraham and Otani 1991; Raymond 2007; Reymann and Frey 2007). While the different induction mechanisms of LTP1, 2, and 3 are now well characterized, it is less clear whether they are also discrete in regard to their expression and maintenance mechanisms.

\section{LTP expression}

One aspect of LTP that continues to be debated concerns the relative contributions of pre- and post-synaptic changes to its expression (Bliss et al. 2003). There is a wealth of evidence for post-synaptic alterations that has been extensively reviewed elsewhere (Yuste and Bonhoeffer 2001; Malinow and Malenka 2002; Derkach et al. 2007). There is also a significant body of work supporting presynaptic changes in LTP expression (Lisman and Raghavachari 2006). Recent optical and quantal studies have revealed unequivocal presynaptic contributions to LTP expression at both early and late time points, but primarily when induced by

\footnotetext{
${ }^{1}$ Corresponding author.

E-mail Clarke111@gmail.com.

Article is online at http://www.learnmem.org/cgi/doi/10.1101//m.2245911.
}

"strong" protocols (Zakharenko et al. 2001; Sokolov et al. 2002; Stanton et al. 2005; Bayazitov et al. 2007; Enoki et al. 2009). Thus, enhanced presynaptic function could have a conditional involvement in LTP expression that may well contribute to discrepancies in the literature.

Other work has focussed on the retrograde signaling that must occur from the post-synaptic induction site to initiate a presynaptic enhancement. Several candidates for this so-called retrograde messenger have been proposed, with the properties of the gaseous neuromodulator nitric oxide (NO) making it a particularly attractive contender (Lancaster 1994). However, the role of NO in hippocampal LTP remains somewhat contentious (Shors and Matzel 1997; Regehr et al. 2009). While most studies indicate that NO augments transmission in the presynaptic cell and promotes synaptic plasticity (Böhme et al. 1991; O'Dell et al. 1991a; Arancio et al. 1995, 1996a; Son et al. 1996), others dispute its role in LTP, particularly in the context of learning (Bannerman et al. 1994a,b), or even whether it acts retrogradely (Ko and Kelly 1999).

\section{LTP maintenance}

New protein synthesis is required to maintain LTP beyond the lifetime of a typical synaptic protein and is also required for long-lasting memories (Abraham and Williams 2008). According to the LTP1, 2, 3 model both LTP2 and 3 are dependent on new protein synthesis, but only LTP3 requires transcription. LTP2 is proposed to involve translation from preexisting mRNA transcripts, perhaps in a synapse-specific manner (Otani et al. 1989; Raymond et al. 2000; Raymond 2007). This mechanistic differentiation has never been systematically tested under the constant experimental conditions of a single study. In addition, little is known about whether there is any overlap between these maintenance mechanisms and the expression mechanisms described above. 


\section{Results}

\section{LTP2 and LTP3 involve enhanced presynaptic function}

It has previously been reported that induction of LTP either chemically or using specific patterns of electrical stimulation is associated with an increase in the rate of FM 1-43 release from CA3 terminals (Zakharenko et al. 2001; Stanton et al. 2005). However, none of these "forms" of LTP have been extensively characterized, and as such, it is unclear how they relate to one another or, more importantly, what the physiological significance of the finding is. In the present study presynaptic vesicle cycling was investigated in well-characterized, identifiable and mechanistically discrete forms of LTP induced by 1TBS, 4TBS, and 8TBS.

In control slices 1TBS resulted in weak LTP that decayed back to baseline $\sim 180 \mathrm{~min}$ post-TBS, with a magnitude in the last 5 min of recording of $5 \% \pm 1 \%(n=5$, Fig. $2 \mathrm{~A}$, below). Four trains of TBS resulted in LTP that had a larger initial magnitude to that induced by 1 TBS and a significantly larger magnitude in the last 5 min of recording, measuring $27 \% \pm 7 \%(n=11$, Fig. 2A, below). Eight trains of TBS induced LTP that had a similar initial magnitude to that produced induced by $4 \mathrm{TBS}$, but a significantly larger final magnitude, measuring $83 \% \pm 13 \%(n=7)$ in the last 5 min of recording (Fig. 2A, below).

Since LTP is best classified on the basis of persistence the post-TBS data were fit with a double exponential decay function as described previously (Raymond et al. 2000; Raymond and Redman 2002). The mean time constant of decay of the slower exponential $(\tau)$ was used as a measure of LTP persistence. In control slices 1TBS resulted in LTP with a $\tau$ of $37 \pm 15 \min (n=3$, Fig. 2B, below). Four trains of TBS induced a more persistent form of LTP, with $\tau$ measuring $117 \pm 14 \mathrm{~min}(n=9$, Fig. 2B, below). Eight trains of TBS produced LTP that was dramatically more persistent than that induced with 1TBS and 4TBS. We were unable to determine a $\tau$ value for 8TBS LTP in these experiments because all control LTP was essentially nondecremental over $2 \mathrm{~h}$ and could not be fit by exponential decay curves. For illustrative purposes the $\tau$ value obtained from a previous set of experiments (Raymond and Redman 2002) has been used (Fig. 2B, below). This 8TBS $\tau$ value is therefore an underestimate and is not used for statistical analysis. Based on these measurements and our previous data using 1TBS, 4TBS, and 8TBS, we classify these forms of LTP as LTP1, LTP2, and LTP3, respectively.

To determine whether presynaptic changes are associated with LTP1, 2, and 3, we simultaneously measured FM 1-43 release from potentiated CA3 terminals in the same slices as the LTP experiments above. FM 1-43 was loaded into terminals of CA3 neurons using a train of electrical stimulation applied to the Schaffer collateral pathway, following bath application of the dye (Fig. 1A). This method resulted in bright punctate staining that could be visualized using two-photon microscopy. The fluorescence of these puncta decreased rapidly following subsequent electrical stimulation, corresponding to diffusion of dye from synaptic vesicles (Fig. 1B). The kinetics of this destaining has previously been shown to strongly correlate with transmitter release at these synapses (Zakharenko et al. 2001).

Under baseline conditions, FM 1-43 destaining kinetics were consistent across each experimental group (baseline $t_{(1 / 2)} 1 \mathrm{TBS}=$ $156 \pm 27 \mathrm{sec}, n=35$ terminals, five slices; $4 \mathrm{TBS}=122 \pm 17 \mathrm{sec}$, $n=50$ terminals, eight slices; 8 TBS $=144 \pm 11 \mathrm{sec}, n=124$ terminals, 15 slices) (Fig. 2C-H). LTP1 was not associated with a change in FM 1-43 destaining at either $80 \mathrm{~min}\left(t_{(1 / 2)}=113 \pm 16 \mathrm{sec}, n=\right.$ 50 terminals, seven slices) or $160 \mathrm{~min}$ post-induction $\left(t_{(1 / 2)}=\right.$ $172 \pm 32 \mathrm{sec}, n=45$ terminals, five slices) (Fig. 2C,D). LTP2 was associated with enhanced exocytosis at $160 \mathrm{~min}$ after induction $\left(t_{(1 / 2)}=58 \pm 7 \mathrm{sec}, n=60\right.$ terminals, six slices, $\left.P<0.05\right)$, but not at $80 \mathrm{~min}\left(t_{(1 / 2)}=95 \pm 8 \mathrm{sec}, n=63\right.$ terminals, eight slices)
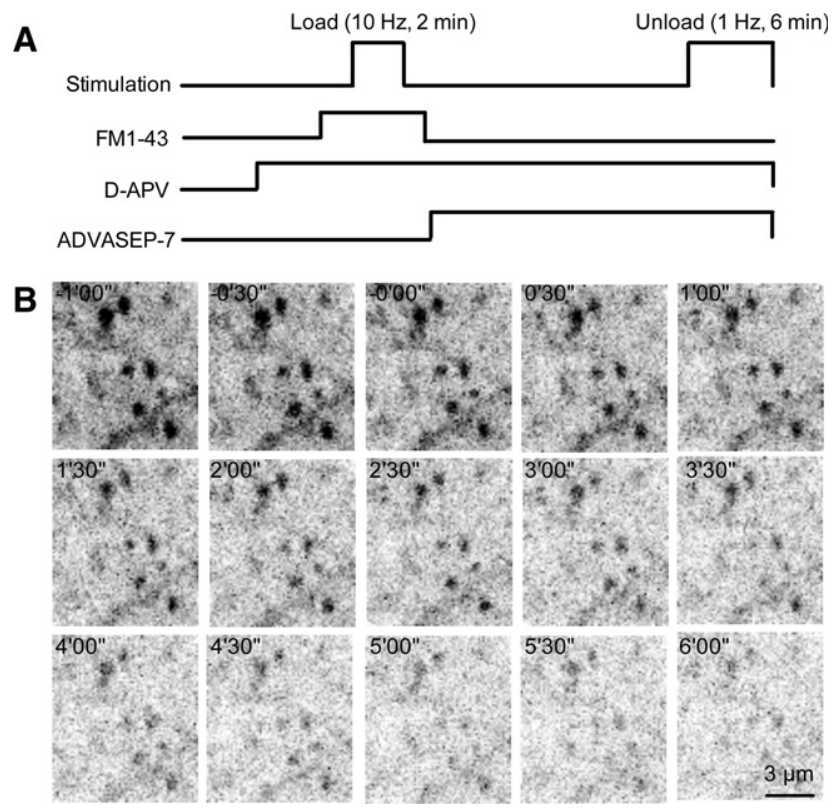

Figure 1. (A) Protocol used to load synaptic terminals with FM 1-43 and measure the kinetics of dye release. Where possible, this protocol was repeated three times within a single slice, once before LTP induction and then $80 \mathrm{~min}$ and $160 \mathrm{~min}$ post-TBS. (B) Two-photon fluorescent images of terminals loaded with FM 1-43 in stratum radiatum of area CA1. Images are of the same field at different times during unloading. Numbers indicate time in minutes and seconds, with zero representing the onset of unloading stimulation ( $1 \mathrm{~Hz}, 6 \mathrm{~min})$.

(Fig. 2E,F). Finally, LTP3 was associated with enhanced exocytosis at both $80 \min \left(t_{(1 / 2)}=59 \pm 6 \mathrm{sec}, n=97\right.$ terminals, 14 slices, $P<$ $0.05)$ and $160 \mathrm{~min}$ post-induction $\left(t_{(1 / 2)}=63 \pm 4 \mathrm{sec}, n=53\right.$ terminals, 10 slices, $P<0.05$ ) (Fig. $2 \mathrm{G}, \mathrm{H}$ ). These findings demonstrate that short-lasting LTP1 is predominantly expressed post-synaptically, and that more persistent LTP2 and 3 recruit a presynaptic expression mechanism.

\section{A single, stable population of terminals before and after LTP}

It is important to verify that sampled puncta were primarily representative of CA3 terminals, and did not include large numbers of GABAergic inhibitory interneurons or astrocytes, both of which endocytose FM 1-43 (Hablitz et al. 2009; Li et al. 2009) and are frequently overlooked in hippocampal FM experiments. If this were the case, one might expect different populations of destaining kinetics to be apparent in our data, as both inhibitory interneurons and astrocytes exhibit heterogeneity in their release properties (McBain and Fisahn 2001; Moulder et al. 2007; Sakaba 2008). However, we found only one population of destaining kinetics, with an average basal $t_{(1 / 2)}$ of $141 \pm 9(n=215$ boutons from 28 slices) (Fig. 3A). It was therefore concluded unlikely that release from astrocytes or inhibitory interneurons were appreciably affecting measurements of destaining from CA3 terminals. This is supported by evidence indicating that only $2.5 \%$ of terminals in the CA3 region are GABAergic (Hiscock et al. 2000). There was also no change in the mean number of release sites measured before and after LTP (basal: $7 \pm 1, n=209$ puncta from 28 slices; LTP1: $9 \pm 2, n=44$ puncta from five slices; LTP2: $9 \pm 2, n=71$ puncta from eight slices; LTP3: $7 \pm 3, n=72$ puncta from 10 slices) (Fig. 3B). This stability in the number of terminals loaded with FM 1-43 suggests that, under these conditions, 

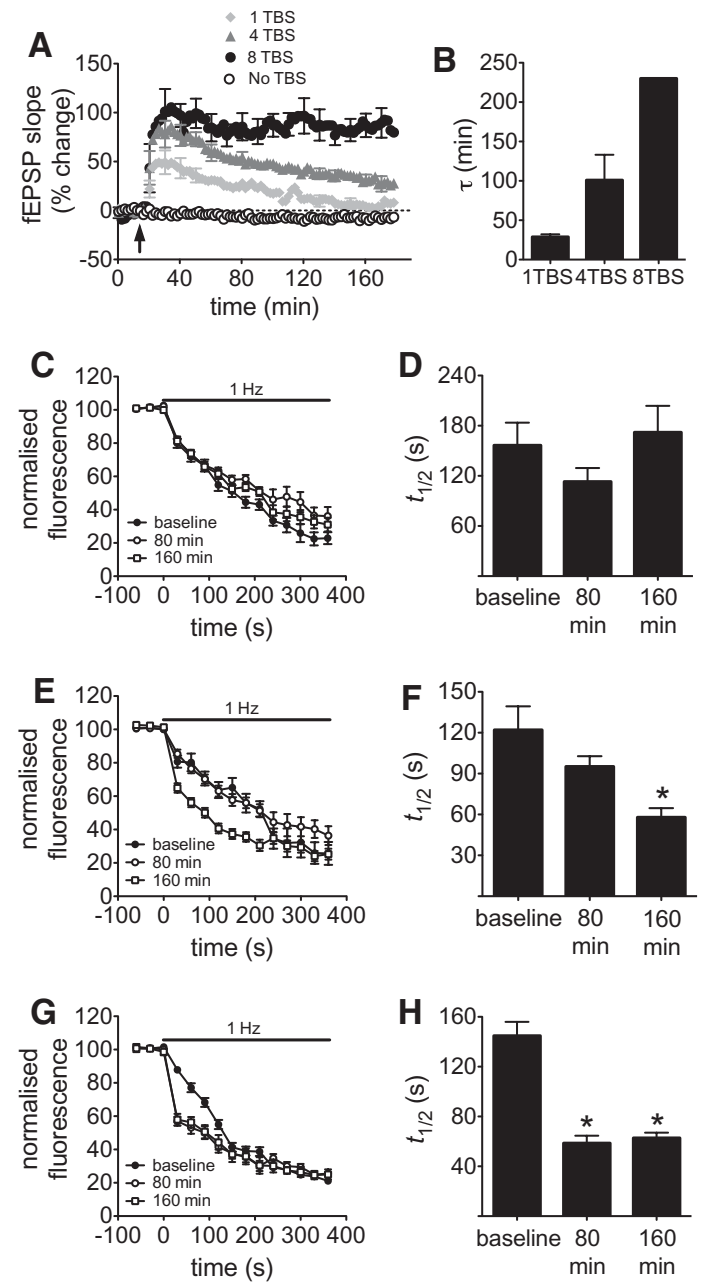

Figure 2. (A) Mean percent change of field excitatory post-synaptic potential (fEPSP) slope from slices receiving 1TBS $(n=4)$, 4TBS $(n=8)$, $8 \mathrm{TBS}(n=5)$ or no TBS $(n=4)$. LTP was induced (arrow) after a 20-min baseline period and recordings continued for $160 \mathrm{~min}$ post-TBS. (B) Decay of LTP1, 2, and 3. The mean time constant of decay, $\tau$, was calculated for LTP induced with 1TBS and 4TBS. A $\tau$ value could not be calculated for LTP induced by 8TBS due to the robust nature of the LTP; therefore, a value has been reproduced from Raymond and Redman (2002). (C) LTP1 is not associated with an enhancement of FM 1-43 release from CA3 terminals. Mean ( \pm SEM) time course of FM 1-43 destaining prior to LTP induction (baseline), $80 \mathrm{~min}$ and $160 \mathrm{~min}$ postinduction. $(D)$ Summary histogram showing average half time of decay $\left(t_{(1 / 2)}\right)$ of FM 1-43 fluorescence for the baseline, $80 \mathrm{~min}$ and $160 \mathrm{~min}$ unload. (E) FM 1-43 destaining time course shows LTP2 is associated with an enhancement of release 160 min post-induction. $(F)$ Summary histogram of average $t_{(1 / 2)}$ in LTP2 experiments. $\left(^{*}\right) P<0.05$. (G) FM $1-43$ destaining time course shows LTP3 is associated with enhanced release at $80 \mathrm{~min}$ and $160 \mathrm{~min}$ post-TBS. $(H)$ Summary histogram of average $t_{(1 / 2)}$ in LTP3 experiments. $\left(^{*}\right) P<0.05$.

induction of LTP1, 2, and 3 does not "unsilence" presynaptically inactive synapses (Voronin et al. 2004).

\section{LTP2 and 3 are NO dependent}

Several studies have shown that inhibition of NO signaling in CA1 prevents the induction of LTP (Böhme et al. 1991; O'Dell et al. 1991a; Schuman and Madison 1991; Haley et al. 1992). However, it is not clear whether NO signaling is important for all forms of LTP now identified at these synapses, or if it is specific for one set of effector mechanisms. In addition, evidence for the prevailing view that during LTP induction NO is released from the post-synaptic cell and acts on the presynaptic terminal to enhance transmitter release (for review, see Regehr et al. 2009) is largely based on indirect measurements of presynaptic function. We therefore determined whether inhibition of NO signaling differentially affects the magnitude and persistence of LTP1, 2, and 3 and if so, whether this correlates with direct measurements of exocytosis. Given that significant increases in exocytosis are observed at the 160-min time point for both LTP2 and 3, we confine this and all subsequent pharmacological analyses to this time point.

Inhibition of nitric oxide synthase (NOS) with $\mathrm{N}$ - $\omega$-nitro-Larginine methyl ester (L-NAME, $100 \mu \mathrm{M}$ ) had no significant effect on either the magnitude at $160 \mathrm{~min}$ post-TBS (control $=5 \pm 1 \%$, $n=5$; L-NAME $=10 \pm 8 \%, n=4$ ) or persistence of LTP1 (control $\tau=37 \pm 15 \mathrm{~min}, n=3$; L-NAME $=72 \pm 10 \mathrm{~min}, n=3$ ) (Fig. $4 \mathrm{~A}$ ). Likewise, no effect of the membrane impermeable NO scavenger 2-(4-carboxyphenyl)-4,4,5,5-tetramethylimidazoline-1-oxyl-3oxide (cPTIO, $40 \mu \mathrm{M}$ ) was observed for LTP1 in terms of persistence (cPTIO $\tau=80 \pm 9 \mathrm{~min}, n=4)$ or magnitude $(2.5 \pm 8 \%, n=4$ ) at 160 min post-TBS (Fig. 5A). Neither drug had any effect on normal synaptic transmission when applied in the absence of TBS (Figs. 4A, 5A). Unsurprisingly, exocytotic rates measured at $160 \mathrm{~min}$ after 1TBS were also unaffected by inhibition of NO signaling by either L-NAME (control $t_{(1 / 2)}=172 \pm 32 \mathrm{sec}$; $\mathrm{L}-\mathrm{NAME}=140 \pm 4.5 \mathrm{sec}, n=75$ terminals from four slices) (Fig. 4B) or cPTIO (132 $\pm 4 \mathrm{sec}, n=140$ terminals from four slices) (Fig. 5B).

In contrast, inhibition of NO signaling significantly reduced LTP2 persistence (control $\tau=117 \pm 14 \mathrm{~min}, n=9$; $\mathrm{L}-\mathrm{NAME}=$ $59 \pm 16 \mathrm{~min}, n=3 ;$ cPTIO $=73 \pm 9 \mathrm{~min}, n=4 ; P<0.05)$ and magnitude (control $=27 \pm 7 \%, n=11$; L-NAME $=10 \pm 5 \%, n=$ 4 ; $\mathrm{CPTIO}=7 \pm 8 \%, n=4 ; P<0.05$ ) (Figs. $4 \mathrm{C}, 5 \mathrm{C}$ ). Both inhibitors also abolished the enhanced exocytosis associated with LTP2 measured $160 \mathrm{~min}$ post-TBS (control $t_{(1 / 2)}=58 \pm 7$ sec; L-NAME $=$ $136 \pm 10 \mathrm{sec}, n=20$ terminals from four slices; $\mathrm{cPTIO}=147 \pm 9$ sec, $n=38$ terminals from four slices) (Figs. 4D, 5D).

Inhibition of NO signaling with L-NAME and cPTIO qualitatively reduced LTP3 $\tau$ values in comparison with previously published data: control $\tau=230 \mathrm{~min}$ (from Raymond and Redman 2002) (L-NAME $=69 \pm 8 \mathrm{~min}, n=4 ;$ cPTIO $=77 \pm 10 \mathrm{~min}, n=$ 3 ); however, statistical analysis of $\tau$ values for LTP3 was not possible in this case. Both inhibitors significantly reduced LTP magnitude at $160 \mathrm{~min}$ post-8TBS (control $=83 \pm 13 \%, n=7$; L-NAME $=$ $1 \pm 6 \%, n=4 ;$ cPTIO $=34 \pm 18 \%, n=3 ; P<0.05$ ) (Figs. $4 \mathrm{E}, 5 \mathrm{E}$ ).
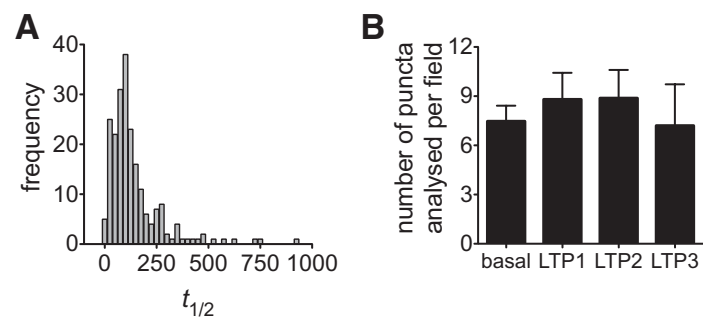

Figure 3. (A) Frequency histogram of half-time of intensity decay $\left(t_{(1 / 2)}\right)$ of individual puncta suggests that measurements are taken from a single population of synaptic vesicles. Data not well fit by a Gaussian distribution ( $P<0.05$, $\mathrm{D}^{\prime}$ Agostino and Pearson omnibus normality test). ( $\left.B\right)$ No difference in the number of puncta analyzed per field before LTP induction (basal) and 160 min post-induction of LTP1, LTP2, and LTP3 indicates there is no "unsilencing" of synapses post-LTP $(P=0.88$, analysis of variance [ANOVA]). 

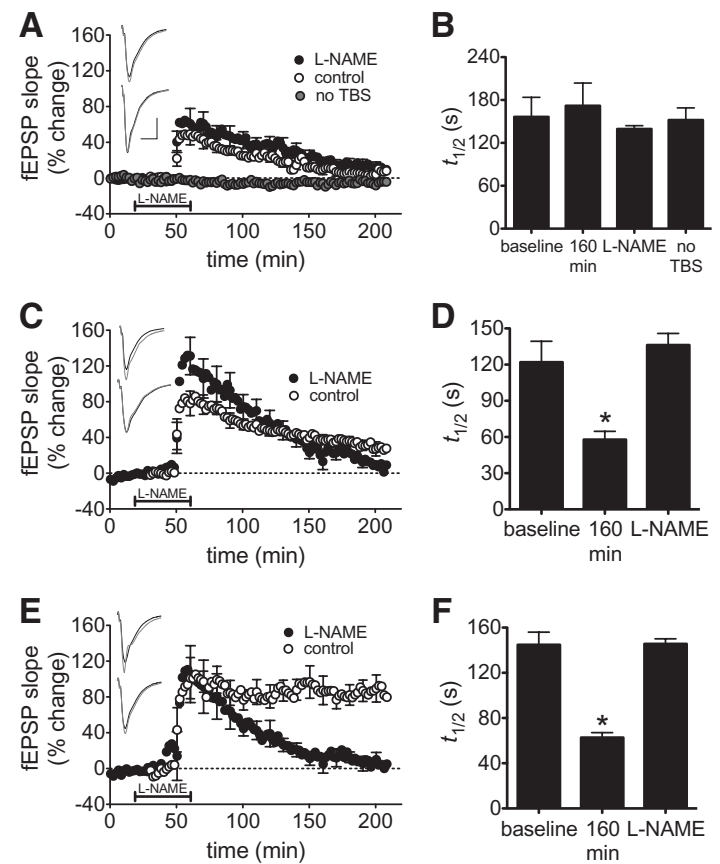

Figure 4. LTP2 and LTP3 and associated enhanced release are dependent on NO synthesis. ( $A$ ) Mean percent change in fEPSP slope in controls and slices incubated with L-NAME $(100 \mu \mathrm{M})$ during the 1TBS induction protocol. Application of L-NAME did not affect LTP1 persistence. Data for nontetanized L-NAME incubated slices are also plotted. (Inset) Representative fEPSPs for the period immediately prior to LTP induction (black) and recording termination (gray). (Top) Control, (bottom) L-NAME. Scale bars $=1 \mathrm{mV}, 10 \mathrm{msec}$. (B) Histogram of mean FM 1-43 destaining kinetics $\left(t_{(1 / 2)}\right)$ in LTP1 experiments showing L-NAME did not affect exocytotic rate 160 min post-1TBS. (C) L-NAME reduced LTP2 persistence and $(D)$ eliminated enhanced release at $160 \mathrm{~min}$ post-4TBS. ( $E$ ) L-NAME reduced LTP3 persistence and $(F)$ eliminated enhanced release 160 min post-8TBS. $\left(^{*}\right) P<0.05$.

Inhibition of NO signaling also prevented the enhanced exocytosis associated with LTP3 at $160 \mathrm{~min}$ post-TBS (control $t_{(1 / 2)}=63 \pm$ $4 \mathrm{sec}$; L-NAME $=146 \pm 4 \mathrm{sec}, n=25$ terminals from four slices; cPTIO $=138 \pm 13$ sec, $n=44$ terminals from three slices) (Figs. 4F, 5F).

Although in some cases cPTIO and L-NAME appear to enhance the initial induction of LTP, a significant increase in the maximum fEPSP amplitude was measured only for LTP2 in the presence of L-NAME (control $=86 \pm 18 \%, n=11$; LNAME $=132 \pm 21 \%, n=4)$. Given that we find no significant effect in all other cases and that other reports indicate that neither drug affects peak EPSP magnitude, nor various other post-synaptic properties of these neurons (Zhu and Erdemli 1995; Ko and Kelly 1999), we conclude that the observed effect on LTP2 is not specifically drug related and that inhibition of NO signaling does not generally enhance LTP induction.

The data presented here demonstrate that only the more robust LTP2 and LTP3 require both activation of NOS and diffusion of NO in the extracellular space, and that NO is necessary to trigger the enhanced exocytosis associated with more persistent forms of LTP.

\section{LTP2 and LTP3 are protein synthesis dependent}

Until now LTP1, 2, and 3 have been differentiated on the basis of distinct induction and maintenance mechanisms (Raymond 2007; Reymann and Frey 2007). With regard to maintenance,
LTP1 is proposed to involve post-translational modifications of existing proteins and glutamate receptor trafficking (equivalent to early LTP) (Lovinger et al. 1987; Malenka et al. 1989; O'Dell et al. 1991b; Shi et al. 1999). LTP2 is dependent on protein synthesis but not gene transcription (Raymond et al. 2000). Finally, LTP3 is translation and transcription dependent, equivalent to traditional late LTP (Nguyen et al. 1994; Kandel 2001; Reymann and Frey 2007). To confirm this aspect of the model under constant experimental conditions, either the translation inhibitor anisomycin (ANI, $20 \mu \mathrm{M}$ ) or the transcription inhibitor Actinomycin $\mathrm{D}$ (Act D, $40 \mu \mathrm{M}$ ) were bath applied for $45 \mathrm{~min}$ beginning 20 min prior to LTP induction. Importantly, both drugs do not interfere with synaptic function by actions other than the inhibition of translation and transcription (Linden 1996; Shitaka et al. 1996; Wiegert et al. 2009) and exposure to Act D and ANI had no effect on normal synaptic transmission or FM 1-43 release in the absence of LTP induction (Figs. 6A, 7A).

Inhibition of translation with ANI or transcription with Act $D$ had no effect on LTP1 persistence (control $\tau=37 \pm 15$ min, $n=3$; $\mathrm{ANI}=68 \pm 29 \mathrm{~min}, n=4$; Act $\mathrm{D}=51 \pm 16 \mathrm{~min}, n=4)$ or magnitude at $160 \mathrm{~min}$ post-TBS (control $=5 \pm 1 \%, n=5$; $\mathrm{ANI}=$ $1 \pm 2 \%, n=4$; Act $\mathrm{D}=1 \pm 1 \%, n=4$ ) (Figs. $6 \mathrm{~A}, 7 \mathrm{~A}$ ). This is consistent with this form of LTP depending only on post-translational modifications. Inhibition of translation with ANI significantly reduced LTP2 magnitude at $160 \mathrm{~min}$ post-4TBS (control $=27 \pm$ $7 \%, n=11 ; \mathrm{ANI}=9 \pm 4 \%, n=6 ; P<0.05)$ and enhanced its
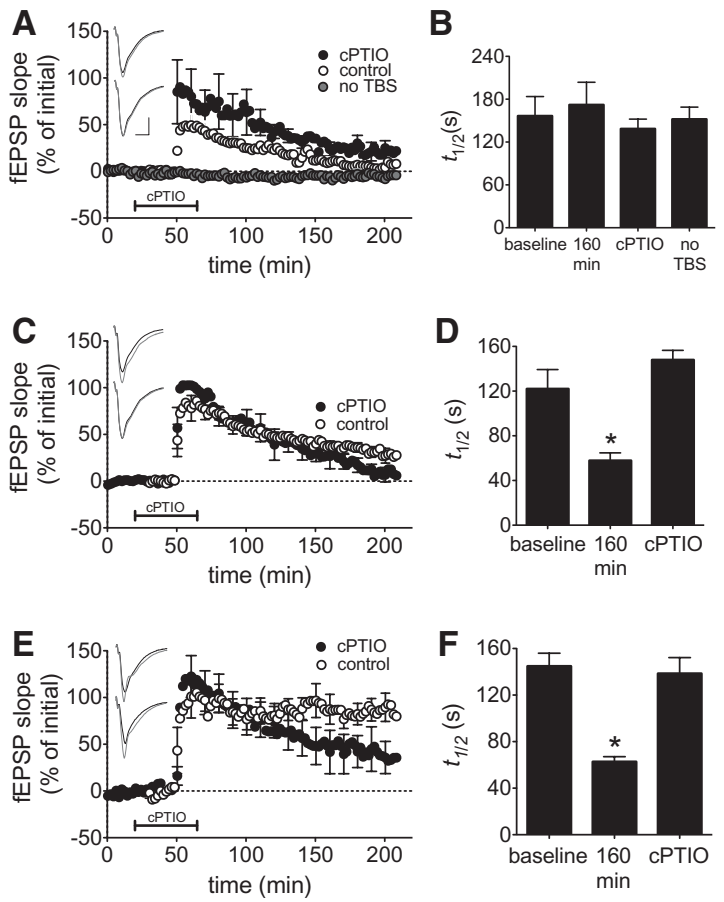

Figure 5. LTP2 and LTP3 and associated enhanced release are dependent on extracellular NO signaling. $(A)$ Mean percent change in fEPSP slope in controls and slices incubated with CPTIO $(40 \mu \mathrm{M})$ during the 1TBS induction protocol. Application of CPTIO did not affect LTP1 persistence. Data for nontetanized CPTIO incubated slices are also plotted. (Inset) Representative fEPSPs for the period immediately prior to LTP induction (black) and recording termination (gray). (Top) Control, (bottom) $\mathrm{m}=$ CPTIO. Scale bars $=1 \mathrm{mV}, 10 \mathrm{msec}$. $(B)$ Histogram of mean FM 1-43 destaining kinetics $\left(t_{(1 / 2)}\right)$ showing CPTIO did not affect LTP1 exocytotic rate 160 min post-1TBS. (C) CPTIO reduced LTP2 persistence and (D) eliminated enhanced release at $160 \mathrm{~min}$ post-4TBS. (E) CPTIO reduced LTP3 persistence and $(F)$ eliminated enhanced release $160 \mathrm{~min}$ post-8TBS. $\left(^{*}\right) P<0.05$. 

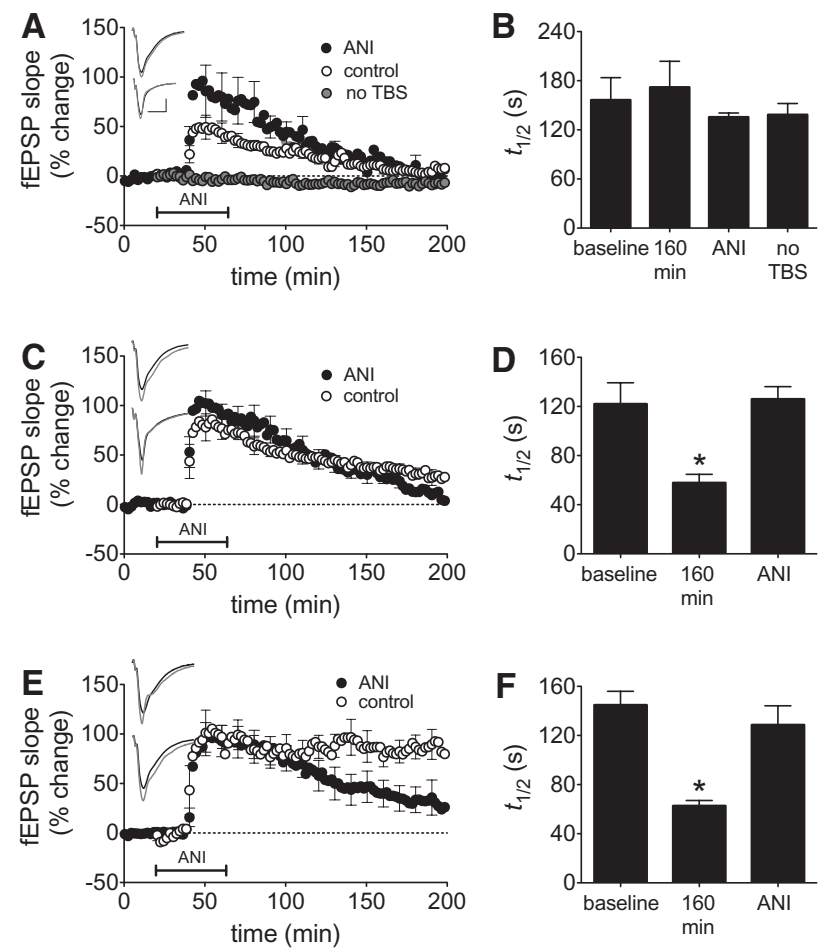

Figure 6. LTP2 and LTP3 and the associated enhanced vesicle release are translation dependent. ( $A$ ) Mean percent change in fEPSP slope in controls and slices incubated with ANI $(20 \mu \mathrm{M})$ during the 1TBS induction protocol. Application of ANI did not affect LTP1 persistence. Data for nontetanized ANI incubated slices are also plotted. (Inset) Representative fEPSPs for the period immediately prior to LTP induction (black) and recording termination (gray). (Top) Control, (bottom) $\mathrm{m}=$ ANI. Scale bars $=1 \mathrm{mV}, 10 \mathrm{msec}$. (B) Histogram of mean FM 1-43 destaining kinetics $\left(t_{(1 / 2)}\right)$ showing ANI did not affect LTP1 exocytotic rate $160 \mathrm{~min}$ post-1TBS. (C) ANI reduced LTP2 persistence and $(D)$ prevented the enhanced release $160 \mathrm{~min}$ post-4TBS. (E) ANI reduced LTP3 persistence and $(F)$ inhibited the enhanced release $160 \mathrm{~min}$ post-8TBS. $\left(^{*}\right) P<0.05$.

decay rate (control $\tau=117 \pm 14 \mathrm{~min}, n=9$; ANI $=38 \pm 9 \mathrm{~min}$, $n=3 ; P<0.05$ ) (Fig. 6C). In contrast, inhibition of transcription with Act D had no effect on LTP2 magnitude $(21 \pm 14 \%, n=5)$ or persistence (Act D $\tau=130 \pm 27 \mathrm{~min}$ ) (Fig. 7C). This is consistent with previously published data showing that LTP2 is dependent on local, mGluR-dependent translation, but not transcription (Raymond et al. 2000). Finally, LTP3 decay was qualitatively enhanced by inhibitors of translation and transcription (control $\tau=230 \mathrm{~min}$ (from Raymond and Redman 2002); ANI $=106 \pm$ $21 \min , n=6$; Act $\mathrm{D}=127 \pm 19 \min , n=3$ ), and LTP magnitude at $160 \mathrm{~min}$ post-8TBS was significantly reduced (control $=83 \pm$ $13 \%, n=5 ;$ ANI $=25 \pm 18 \%, n=6$; Act $\mathrm{D}=27 \pm 14 \%, n=3$; $P<0.05$ ) (Figs. 6E, 7E). Importantly, Act D and ANI did not act by influencing the induction of LTP, as application immediately after 8TBS resulted in the same effects on LTP3 decay as when applied during induction (Fig. 7G). These data provide the first confirmation in one study that LTP1 is neither transcription nor translation dependent, LTP2 is translation but not transcription dependent, and LTP3 is dependent on both transcription and translation.

\section{The presynaptic component of LTP is protein} synthesis dependent

Although the requirement for protein synthesis in longlasting LTP is generally associated with post-synaptic expression mechanisms, our data suggest an intriguing possibility that enhanced exocytosis is also protein synthesis dependent. As expected, neither Act D nor ANI had any effect on LTP1 exocytotic rate measured at $160 \mathrm{~min}$ post-TBS (control $t_{(1 / 2)}=172 \pm 32 \mathrm{sec}$; $\mathrm{ANI}=136 \pm 5 \mathrm{sec}, n=52$ terminals from four slices; Act $\mathrm{D}=$ $134 \pm 3 \mathrm{sec}, n=88$ terminals from four slices) (Figs. 6B, 7B). Together with the LTP1 decay data this supports the idea that LTP1 is expressed post-synaptically and independently of protein synthesis.

In concordance with LTP2 decay data ANI prevented the increase in exocytotic rate that was observed in controls 160 min post-LTP2 induction, whereas Act D had no significant effect (control $t_{(1 / 2)}=58 \pm 7 \mathrm{sec}$; ANI $=126 \pm 10 \mathrm{sec}, n=91$ terminals from six slices; Act $\mathrm{D}=56 \pm 5 \mathrm{sec}, n=47$ terminals from five slices) (Figs. 6D, 7D).
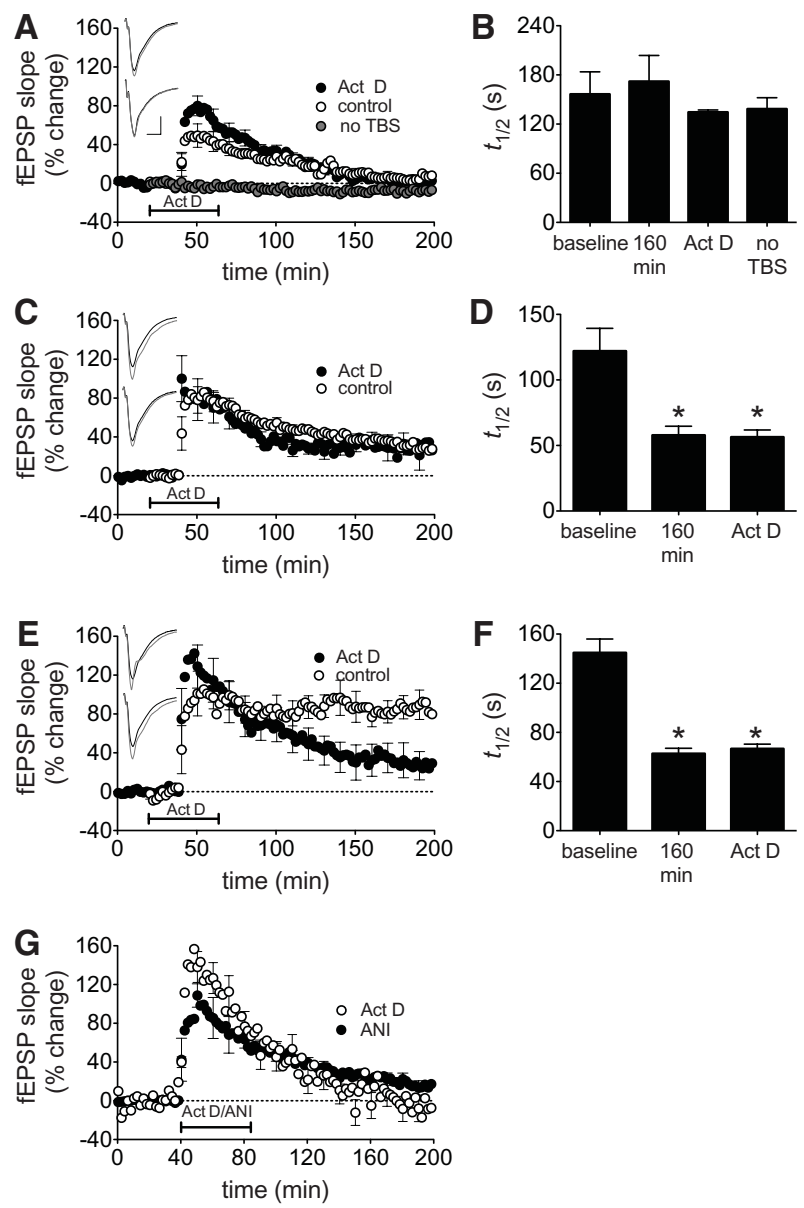

Figure 7. LTP3 is transcription dependent and presynaptic LTP expression is transcription independent. $(A)$ Mean percent change in fEPSP slope in controls and slices incubated with Act D $(40 \mu \mathrm{M})$ during the 1TBS induction protocol. Application of Act D did not affect LTP1 persistence. Data for nontetanized Act D incubated slices are also plotted. (Inset) Representative fEPSPs for the period immediately prior to LTP induction (black) and recording termination (gray). (Top) Control, (bottom) $\mathrm{m}=$ Act $\mathrm{D}$. Scale bars $=1 \mathrm{mV}, 10 \mathrm{msec}$. (B) Histogram of mean FM 1-43 destaining kinetics $\left(t_{(1 / 2)}\right)$ showing Act $D$ did not affect LTP1 exocytotic rate 160 min post-1TBS. (C) Act D did not affect LTP2 persistence or $(D)$ enhanced release at $160 \mathrm{~min}$ post-4TBS. (E) Act D reduced LTP3 persistence but $(F)$ did not affect enhanced release 160 min post-8TBS. (*) $P<0.05$. (G) LTP3 decay was equally affected when application of Act D or ANI occurred immediately post-TBS. 
Intriguingly, while the enhanced exocytotic rate associated with LTP3 was also prevented by ANI, it remained unaffected by inhibition of transcription with Act $\mathrm{D}$ (control $t_{(1 / 2)}=63 \pm 4$ sec; $\mathrm{ANI}=128 \pm 16 \mathrm{sec}, n=36$ terminals from four slices; Act $\mathrm{D}=67 \pm 4 \mathrm{sec}, n=53$ terminals from five slices) (Figs. 6F, 7F).

These data demonstrate that the enhanced presynaptic function associated with persistent LTP only depends upon translation and does not require gene transcription.

\section{Discussion}

It is increasingly accepted that LTP is not a unitary phenomenon and that even within one population of synapses different forms of LTP can coexist. Our findings confirm and elaborate upon the LTP1, 2, and 3 classification model at hippocampal CA3-CA1 synapses. LTP1, 2, and 3 were initially separated on the basis of persistence, but in recent times the differentiation has been expanded to include discrete $\mathrm{Ca}^{2+}$ signaling mechanisms (Raymond and Redman 2002, 2006) and different requirements for post-synaptic action potentials during induction (Raymond 2008). We now show that the recruitment of a presynaptic expression mechanism further distinguishes LTP2 and LTP3 from LTP1. Using a more precise categorization of LTP with well-characterized and discrete mechanisms, our results elaborate on previous studies that showed persistent forms of LTP are associated with presynaptic functional changes (Huang and Kandel 1994; Zakharenko et al. 2001, 2003; Huang et al. 2005; Stanton et al. 2005; Ahmed and Siegelbaum 2009).

\section{Role of new protein synthesis in LTP2 and LTP3}

We have now confirmed a central feature of the LTP1, 2, and 3 model by showing that the maintenance of LTP3 is both transcription and translation dependent, whereas LTP2 maintenance requires only translation and LTP1 is protein synthesis independent. Protein synthesis-dependent LTP (historically known as late LTP) has been extensively characterized in the hippocampus, generally involving CREB-mediated transcription of key plasticity-related gene products (Abraham 2003; Pittenger and Kandel 2003; Benito and Barco 2010). In this case, mRNA can be trafficked to the dendrites where it is locally translated (Steward and Schuman 2003), or translated at the soma and the newly synthesized proteins trafficked to the dendrites to be utilized by "tagged" synapses (Frey and Frey 2008). On the other hand, a form of LTP requiring transcription-independent protein synthesis was first demonstrated in the dentate gyrus in vivo (Otani et al. 1989) and was later also identified in CA1 in vitro (Raymond et al. 2000; Gelinas and Nguyen 2005). In these studies LTP persistence was dependent on local protein synthesis, presumably from a constitutive pool of dendritic mRNA, triggered by activation of either Group 1 metabotropic glutamate receptors or $\beta$-adrenergic receptors.

In this study, both Act D and ANI were applied using concentrations and application durations that are known to induce substantial inhibition of transcription and translation. Here we applied the transcription inhibitor Act D for $45 \mathrm{~min}$, beginning 20 min preinduction, which is similar to other studies (Huber et al. 2000; Kelleher et al. 2004; Levenson et al. 2004) and is sufficient to achieve substantial transcription reduction (Perry and Kelley 1970). The translation inhibitor ANI was also applied for a similar duration to that used in other studies (Stanton and Sarvey 1984; Huang and Kandel 1994; Hardingham et al. 1999; Gelinas and Nguyen 2005) and at a concentration known to block protein synthesis by $>80 \%$ (Stanton and Sarvey 1984). In addition to its role in protein synthesis inhibition, ANI is also known to activate the p38/MAPK pathway under some conditions
(Shifrin and Anderson 1999), and can elicit synaptic depression at specific frequencies (Xiong et al. 2006). We conclude it unlikely that these or other nonspecific effects of ANI and Act D are significant in our experiments, as inclusion of both drugs in the bath did not appreciably affect the magnitude of the fEPSP (Figs. 6A, 7A).

Until now there has been little to link the protein synthesis requirements of LTP2 and LTP3 to a presynaptic expression mechanism. Our data show that in the absence of translation the enhanced presynaptic function associated with the maintenance of both LTP2 and LTP3 is eliminated. Interestingly, although LTP3 as measured via fEPSPs is significantly impaired by Act D, the presynaptic expression component remains intact. This suggests that LTP3 maintenance also involves a significant post-synaptic expression mechanism. The potentiation remaining in the absence of transcription likely reflects the presynaptic component, whereas the post-synaptic expression mechanism, which presumably underlies the greater persistence of LTP3 over LTP2, appears to be supported by new transcription. It should be noted however, that since the CA3 cell bodies containing the presynaptic transcriptional machinery are removed during our hippocampal slicing protocol, it remains possible that presynaptic transcription may contribute to LTP persistence in vivo. Indeed, changes in the levels of several synapse-related transcripts have been observed in area CA3 following LTP induction at Schaffer collateral synapses (for review, see Abraham and Williams 2003).

Previous studies using FM 1-43 or synaptopHlourin-expressing mice suggest that L-type voltage-dependent $\mathrm{Ca}^{2+}$ channel (LVDCC) activation is necessary for LTP involving a presynaptic component (Zakharenko et al. 2001; Bayazitov et al. 2007). Certainly, with respect to LTP3 our data are consistent with this since LTP3 is dependent on somatic $\mathrm{Ca}^{2+}$ signaling via L-VDCCs (Raymond and Redman 2006). However, our model suggests that L-VDCCs are not obligatory for activating a presynaptic LTP expression mechanism since LTP2, which is independent of L-VDCCs (Raymond and Redman 2002, 2006), also involves a presynaptic enhancement. Rather, our data suggest that L-VDCCs are upstream of a crucial common effector of presynaptic changeprotein synthesis-and that different signaling pathways (e.g., internal $\mathrm{Ca}^{2+}$ release via $\mathrm{IP}_{3}$ receptors) activated by weaker stimulation protocols may also suffice.

The translation required for the presynaptic component of both forms of LTP could either occur post-synaptically, or perhaps more interestingly presynaptically in response to NO. Local postsynaptic protein synthesis has been extensively characterized (Steward and Levy 1982; Sutton and Schuman 2006; Bramham and Wells 2007) and is often associated with LTP. There is also mounting evidence to support a role for translation in presynaptic terminals (for review, see Akins et al. 2009). Local presynaptic protein synthesis has been established in both immature and mature rat hippocampal cultures (Sebeo et al. 2009), in forms of LTP and long-term depression in Xenopus nerve-muscle cultures (Zhang and Poo 2002), in corticostriatal fibers (Yin et al. 2006), and in hippocampal mossy fiber-CA3 synapses (Huang and Hsu 2004).

\section{Onset of presynaptic expression}

Another interesting aspect of the current findings is the difference in onset timing of the presynaptic expression. While enhanced presynaptic function was only apparent for LTP2 at the $160 \mathrm{~min}$ post-TBS unload, enhanced release was also observed for LTP3 at 80 min post-induction. Other studies have reported a slow onset for the presynaptic expression associated with more persistent forms of LTP (Bayazitov et al. 2007) as is also observed here; however, this is the first demonstration that different forms of LTP may recruit changes in presynaptic expression at different times. Based on these results it seems likely that 8TBS stimulation may more 
rapidly trigger the translation that is required for enhanced release. Indeed, the additional dendritic $\mathrm{Ca}^{2+}$ signal evoked by 8TBS over 4TBS (Raymond and Redman 2006) could more effectively activate $\mathrm{Ca}^{2+}$-dependent dendritic translation (Atkins et al. 2004). Such temporal coordination of expression mechanisms may act to more effectively enhance synaptic strength, as the earlier onset of presynaptic changes reinforces the postsynaptic signaling events. Further investigations using methods with higher temporal resolution are necessary to address these issues.

\section{Nitric oxide}

Our studies have also indentified a role for NO signaling in the persistence of LTP2 and 3, and the associated enhanced release. While a number of studies have reported a dependence of LTP persistence on NO signaling (Schuman and Madison 1991; Haley et al. 1992; Arancio et al. 1996a,b; Ko and Kelly 1999; Bon and Garthwaite 2001), this is the first study in which unequivocal NO-dependent effects on both LTP and presynaptic function have been directly measured. One previous study observed a partial effect of NO antagonism on FM 1-43 kinetics, but no effect on LTP (Stanton et al. 2005). The general scheme for NO action in hippocampal LTP is that $\mathrm{Ca}^{2+}$ influx via NMDA receptors activates NOS, which synthesizes NO from L-arginine (Boehning and Snyder 2003; Garthwaite 2008). Once synthesized, NO diffuses out of the post-synaptic cell and acts on soluble guanylyl cyclase in the presynaptic neuron, switching on cGMP-dependent protein kinases. Our results are consistent with this hypothesis, showing that NO production and diffusion into the extracellular space is necessary for LTP-associated presynaptic enhancement. Alternatively, NO may act on astrocytes or other intermediary cells that then initiate signaling to the presynaptic neuron. Indeed, there is increasing evidence to support a role for astrocytes in the regulation of LTP in culture and slice preparations (Filosa et al. 2009; Bélair et al. 2010; Henneberger et al. 2010). Although it is possible that NO is acting post-synaptically to prolong LTP (Ko and Kelly 1999) it seems unlikely in our experiments given the concomitant inhibition of the LTP-associated presynaptic enhancement by $\mathrm{NO}$ antagonists. If this were the case NO would have to be involved in the release of a second retrograde messenger.

Nevertheless, it is interesting to speculate whether NO is upstream of or downstream from the protein synthesis that we now show is necessary for presynaptic LTP expression. NO production per se could depend upon local dendritic protein synthesis that is known to be important for some forms of LTP (Raymond et al. 2000; Gelinas and Nguyen 2005), although evidence so far suggests increased NOS expression only at the very late stages of LTP maintenance (Abraham and Williams 2003). Alternatively, a NO-cGMP-MAP kinase pathway has been implicated in synaptic plasticity and memory (Izumi et al. 2008; Ota et al. 2008) and MAPK/ERK signaling is a well-known activator of local protein synthesis in dendrites (Sutton and Schuman 2005). Since it is unlikely that NO is acting post-synaptically in our experiments, it is possible that this cascade is activated presynaptically to trigger local protein synthesis in or near synaptic terminals. An alternate possibility is that NO signaling acts in parallel with protein synthesis and that both pathways therefore act synergistically to trigger enhanced exocytosis.

\section{Concluding remarks}

The LTP1, 2, and 3 model is considerably strengthened by the addition of our current findings. It is now abundantly clear that CA3-CA1 synapses can support at least three mechanistically discrete forms of LTP. LTP1 is dependent entirely on local, post- synaptic induction, expression, and maintenance mechanisms. LTP2 induction involves dendritic $\mathrm{Ca}^{2+}$ signaling, modulated by backpropagating action potentials, and both pre- and postsynaptic expression mechanisms maintained by local dendritic and/or presynaptic protein synthesis. Finally, LTP3 involves cell-wide mechanisms, including somatic $\mathrm{Ca}^{2+}$ signaling during induction, a presynaptic expression component dependent on protein synthesis, and a post-synaptic expression mechanism supported by gene transcription. There is evidence for a similar LTP repertoire at the perforant path input to the dentate gyrus (Abraham and Otani 1991; Reymann and Frey 2007) and whether such variants exist in other synaptic pathways outside the hippocampus will be an interesting question for future studies. Another important question is whether each form of LTP subserves a different function in learning and memory processing. We contend that many of the controversies in CA1 LTP research have arisen from the coexistence of LTP1, 2, and 3, and that appreciation of their individual characteristics and underlying mechanisms should assist in the design and interpretation of future investigations.

\section{Materials and Methods}

\section{Slice preparation and electrophysiology}

Experiments were performed in accordance with the Australian National University Animal Experimentation Ethics Committee guidelines. Male Wistar rats (6-8 wk) were anesthetized with isofluorane via inhalation, decapitated, and the brains submerged in ice-cold dissecting solution (MM: $124 \mathrm{NaCl}, 3.2 \mathrm{KCl}, 1.25$ $\mathrm{NaH}_{2} \mathrm{PO}_{4}, 26 \mathrm{NaHCO}_{3}, 0.5 \mathrm{CaCl}_{2}, 7 \mathrm{MgCl}_{2}$ and 10 D-glucose, equilibrated with $\left.95 \% \mathrm{O}_{2}-5 \% \mathrm{CO}_{2}\right)$. Transverse hippocampal slices $(400 \mu \mathrm{m})$ were prepared and area CA3 was removed to reduce potential hyperexcitability. Slices were immediately transferred to a holding solution as above, except the $\mathrm{Ca}^{2+}, \mathrm{Mg}^{2+}$ and D-glucose concentrations were adjusted to $2.5 \mathrm{mM}, 1.3 \mathrm{mM}$, and $25 \mathrm{mM}$, respectively. Slices were maintained at $34^{\circ} \mathrm{C}$ for at least 30-40 min before recording.

Slices were perfused in a continuous flow $\left(\sim 2 \mathrm{~mL} \mathrm{~min}^{-1}\right)$ of recording solution (as per holding solution) at $32-34^{\circ} \mathrm{C}$. Field excitatory postsynaptic potentials (fEPSPs) were recorded from stratum radiatum in area CA1 using glass microelectrodes $(2-5$ $\mathrm{M} \Omega$ ) filled with recording solution. Baseline synaptic responses were evoked by stimulation of the Schaffer collateral/commissural axons at $0.033 \mathrm{~Hz}$ (0.1-msec pulse width) with a Teflon-insulated tungsten bipolar electrode placed 100-200 $\mu \mathrm{m}$ away from the recording pipette. The stimulation intensity was adjusted to evoke fEPSPs of approximately two-thirds maximal amplitude. Only fEPSPs between $1 \mathrm{mV}$ and $4 \mathrm{mV}$ in amplitude were accepted. LTP was induced by TBS, consisting of trains of $10 \times 100 \mathrm{~Hz}$ bursts (five pulses/burst) with a 200-msec interburst interval, at the test pulse intensity. When multiple trains were delivered (i.e., 4TBS and 8TBS) the intertrain interval was $30 \mathrm{sec}$.

\section{FM 1-43 loading and unloading}

After recording stable Schaffer collateral-evoked fEPSPs for at least 20 min synaptic vesicles were loaded by delivering a train of 1200 stimuli (at $10 \mathrm{~Hz})$ in the presence of FM $1-43(5 \mu \mathrm{M}$, Biotium Inc.) and D-APV (100 $\mu \mathrm{M}$, Tocris) (Fig. 1A). The dye application continued for 1 min past the duration of the loading stimuli to ensure completion of endocytosis and dye uptake. FM 1-43 was then washed out in the presence of ADVASEP-7 (0.5 mM, Biotium) for $20 \mathrm{~min}$ to remove any extracellularly bound dye (Kay et al. 1999). Destaining was achieved by stimulating at $1 \mathrm{~Hz}$ for $6 \mathrm{~min}$ in the presence of ADVASEP-7 and D-APV. Results from preliminary experiments demonstrated that this protocol maximally unloaded the dye (data not shown). In addition, the rate of destaining was both $\mathrm{Ca}^{2+}$ - and temperature-dependent in a manner consistent with it being a valid measure of exocytosis (data not shown; Zakharenko et al. 2001). Importantly, three bouts of 
staining and destaining were performed within one slice (baseline, 80-min and 160-min post-LTP induction) allowing for intraslice comparisons of the effects of LTP on exocytotic rate at time points following LTP1, 2, and 3 induction.

\section{Two-photon imaging}

Fluorescence of labeled release sites was visualized using a Zeiss LSM 510 two-photon laser-scanning microscope with a water immersion objective (Achroplan $40 \times / 0.75 \mathrm{~W}$ ). Two-photon excitation was achieved with a Ti:Sapphire laser tuned to $840 \mathrm{~nm}$. All fields imaged were typically $10-20 \mu \mathrm{m}$ deep, and were $40-80 \mu \mathrm{m}$ away from the stimulating electrode. A series of $5-10$ images $(512 \times 512,0.15 \mu \mathrm{m} /$ pixel in the $x-y$ axes) were taken at $1-2 \mu \mathrm{m}$ intervals in the $z$-plane. These $z$-stacks were repeated every $30 \mathrm{sec}$, beginning $1 \mathrm{~min}$ prior to and during the unloading stimulation. In offline analyses, maximal z-projections were generated from each image series to create one image per 30 -sec time point. Circular regions of interest were defined around the center of brightly stained punctate fluorescent spots, and 2 69 terminals and three background regions were measured at each time point. Only puncta that satisfied four predetermined criteria were included in analysis. These were: (1) diameter of $0.5-1 \mu \mathrm{m},(2)$ approximately circular shape, (3) minimal $x-y$ movement, and (4) activity-dependent destaining that was well fit by a first order exponential decay function. A fluorescence time course was generated by subtracting the average background fluorescence at each time point then normalizing the fluorescence of each punctum at each time point to the average of the prestimulus values. Photobleaching was corrected for by normalizing to the average background fluorescence at the corresponding time point throughout the unload stimulation. The half-time of decay of fluorescence intensity during unloading $\left(t_{(1 / 2)}\right)$ was calculated for each punctum from single exponential decay curves fitted to the 6 min of stimulus-induced destaining.

\section{Data analysis}

Two-tailed unpaired Student's $t$-tests were used to determine statistical significance at the 95\% confidence level for all analysis (unless otherwise stated). All data represented as mean \pm SEM.

\section{Acknowledgments}

This research was funded by The Australian National University. We are grateful to Garry Rodda for excellent technical assistance.

\section{References}

Abraham W. 2003. How long will long-term potentiation last? Philos Trans $R$ Soc Lond B Biol Sci 358: 735-744.

Abraham W, Otani S. 1991. Macromolecules and the maintenance of long-term potentiation. In Kindling and synaptic plasticity — the legacy of Graham Goddard (ed. F Morrell), pp. 92-109. Birkhauser, Boston, MA.

Abraham W, Williams J. 2003. Properties and mechanisms of LTP maintenance. Neuroscientist 9: 463-474.

Abraham W, Williams J. 2008. LTP maintenance and its protein synthesis-dependence. Neurobiol Learn Mem 89: 260-268.

Ahmed MS, Siegelbaum SA. 2009. Recruitment of N-Type Ca(2+) channels during LTP enhances low release efficacy of hippocampal CA1 perforant path synapses. Neuron 63: 372-385.

Akins MR, Berk-Rauch HE, Fallon JR. 2009. Presynaptic translation: Stepping out of the postsynaptic shadow. Front Neural Circuits 3: 17. doi: 10.3389/neuro.04.017.2009.

Arancio O, Kandel ER, Hawkins RD. 1995. Activity-dependent long-term enhancement of transmitter release by presynaptic 3',5'-cyclic GMP in cultured hippocampal neurons. Nature 376: 74-80.

Arancio O, Kiebler M, Lee CJ, Lev-Ram V, Tsien RY, Kandel ER, Hawkins RD. 1996a. Nitric oxide acts directly in the presynaptic neuron to produce long-term potentiation in cultured hippocampal neurons. Cell 87: $1025-1035$.

Arancio O, Lev-Ram V, Tsien RY, Kandel ER, Hawkins RD. 1996b. Nitric oxide acts as a retrograde messenger during long-term potentiation in cultured hippocampal neurons. J Physiol (Paris) 90: 321-322.
Atkins CM, Nozaki N, Shigeri Y, Soderling TR. 2004. Cytoplasmic polyadenylation element binding protein-dependent protein synthesis is regulated by calcium/calmodulin-dependent protein kinase II. J Neurosci 24: 5193-5201.

Bannerman DM, Chapman PF, Kelly PA, Butcher SP, Morris RG. 1994a. Inhibition of nitric oxide synthase does not impair spatial learning. J Neurosci 14: 7404-7414.

Bannerman DM, Chapman PF, Kelly PA, Butcher SP, Morris RG. 1994b. Inhibition of nitric oxide synthase does not prevent the induction of long-term potentiation in vivo. J Neurosci 14: 7415-7425.

Bayazitov I, Richardson R, Fricke R, Zakharenko S. 2007. Slow presynaptic and fast postsynaptic components of compound long-term potentiation. J Neurosci 27: 11510-11521.

Bélair E-L, Vallée J, Robitaille R. 2010. In vivo long-term synaptic plasticity of glial cells. J Physiol (Lond) 588: 1039-1056.

Benito E, Barco A. 2010. CREB's control of intrinsic and synaptic plasticity: Implications for CREB-dependent memory models. Trends Neurosci 35: $235-240$

Bliss T, Collingridge G. 1993. A synaptic model of memory: Long-term potentiation in the hippocampus. Nature 361: 31-39.

Bliss T, Collingridge G, Morris R. 2003. Introduction. Long-term potentiation and structure of the issue. Philos Trans R Soc Lond B Biol Sci 358: $607-611$.

Boehning D, Snyder SH. 2003. Novel neural modulators. Annu Rev Neurosci 26: $105-131$.

Böhme GA, Bon C, Stutzmann JM, Doble A, Blanchard JC. 1991. Possible involvement of nitric oxide in long-term potentiation. Eur J Pharmacol 199: $379-381$.

Bon CL, Garthwaite J. 2001. Exogenous nitric oxide causes potentiation of hippocampal synaptic transmission during low-frequency stimulation via the endogenous nitric oxide-cGMP pathway. Eur J Neurosci 14: 585-594.

Bramham CR, Wells DG. 2007. Dendritic mRNA: Transport, translation and function. Nat Rev Neurosci 8: 776-789.

Derkach VA, Oh MC, Guire ES, Soderling TR. 2007. Regulatory mechanisms of AMPA receptors in synaptic plasticity. Nat Rev Neurosci 8: 101-113.

Enoki R, Hu Y-L, Hamilton D, Fine A. 2009. Expression of long-term plasticity at individual synapses in hippocampus is graded, bidirectional, and mainly presynaptic: Optical quantal analysis. Neuron 62: $242-253$.

Filosa A, Paixão S, Honsek SD, Carmona MA, Becker L, Feddersen B, Gaitanos L, Rudhard Y, Schoepfer R, Klopstock T, et al. 2009. Neuron-glia communication via EphA4/ephrin-A3 modulates LTP through glial glutamate transport. Nat Neurosci 12: 1285-1292.

Frey S, Frey JU. 2008. "Synaptic tagging" and "cross-tagging" and related associative reinforcement processes of functional plasticity as the cellular basis for memory formation. Prog Brain Res 169: 117-143.

Garthwaite J. 2008. Concepts of neural nitric oxide-mediated transmission. Eur J Neurosci 27: 2783-2802.

Gelinas JN, Nguyen PV. 2005. Beta-adrenergic receptor activation facilitates induction of a protein synthesis-dependent late phase of long-term potentiation. J Neurosci 25: 3294-3303.

Hablitz JJ, Mathew SS, Pozzo-Miller L. 2009. GABA vesicles at synapses: Are there 2 distinct pools? Neuroscientist 15: 218-224.

Haley JE, Wilcox GL, Chapman PF. 1992. The role of nitric oxide in hippocampal long-term potentiation. Neuron 8: 211-216.

Hardingham GE, Chawla S, Cruzalegui FH, Bading H. 1999. Control of recruitment and transcription-activating function of CBP determines gene regulation by NMDA receptors and L-type calcium channels. Neuron 22: 789-798.

Henneberger C, Papouin T, Oliet SHR, Rusakov DA. 2010. Long-term potentiation depends on release of D-serine from astrocytes. Nature 463: $232-236$.

Hiscock JJ, Murphy S, Willoughby JO. 2000. Confocal microscopic estimation of GABAergic nerve terminals in the central nervous system. J Neurosci Methods 95: 1-11.

Huang C-C, Hsu K-S. 2004. Local protein synthesis and GABAB receptors regulate the reversibility of long-term potentiation at murine hippocampal mossy fibre-CA3 synapses. J Physiol (Lond) 561: 91-108.

Huang YY, Kandel ER. 1994. Recruitment of long-lasting and protein kinase A-dependent long-term potentiation in the CA1 region of hippocampus requires repeated tetanization. Learn Mem 1: 74-82.

Huang Y, Zakharenko S, Schoch S, Kaeser P, Janz R, Sudhof T, Siegelbaum S, Kandel E. 2005. Genetic evidence for a protein-kinase-A-mediated presynaptic component in NMDA-receptor-dependent forms of long-term synaptic potentiation. Proc Natl Acad Sci 102: 9365-9370.

Huber KM, Kayser MS, Bear MF. 2000. Role for rapid dendritic protein synthesis in hippocampal mGluR-dependent long-term depression. Science 288: 1254-1257.

Izumi Y, Tokuda K, Zorumski CF. 2008. Long-term potentiation inhibition by low-level N-methyl-D-aspartate receptor activation involves 
calcineurin, nitric oxide, and p38 mitogen-activated protein kinase. Hippocampus 18: 258-265.

Kandel ER. 2001. The molecular biology of memory storage: A dialogue between genes and synapses. Science 294: 1030-1038.

Kay A, Alfonso A, Alford S, Cline H, Holgado A, Sakmann B, Snitsarev V, Stricker T, Takahashi M, Wu L. 1999. Imaging synaptic activity in intact brain and slices with FM1-43 in C. elegans, lamprey, and rat. Neuron 24: 809-817.

Kelleher RJ, Govindarajan A, Tonegawa S. 2004. Translational regulatory mechanisms in persistent forms of synaptic plasticity. Neuron 44: $59-73$.

Ko GY, Kelly PT. 1999. Nitric oxide acts as a postsynaptic signaling molecule in calcium/calmodulin-induced synaptic potentiation in hippocampal CA1 pyramidal neurons. J Neurosci 19: 6784-6794.

Lancaster JR. 1994. Simulation of the diffusion and reaction of endogenously produced nitric oxide. Proc Natl Acad Sci 91: 8137-8141.

Levenson JM, O'Riordan KJ, Brown KD, Trinh MA, Molfese DL, Sweatt JD. 2004. Regulation of histone acetylation during memory formation in the hippocampus. J Biol Chem 279: 40545-40559.

Li D, Hérault K, Oheim M, Ropert N. 2009. FM dyes enter via a store-operated calcium channel and modify calcium signaling of cultured astrocytes. Proc Natl Acad Sci 106: 21960-21965.

Linden DJ. 1996. A protein synthesis-dependent late phase of cerebellar long-term depression. Neuron 17: 483-490.

Lisman J, Raghavachari S. 2006. A unified model of the presynaptic and postsynaptic changes during LTP at CA1 synapses. Sci STKE 2006: pre11.

Lovinger DM, Wong KL, Murakami K, Routtenberg A. 1987. Protein kinase C inhibitors eliminate hippocampal long-term potentiation. Brain Res 436: $177-183$.

Malenka R, Kauer J, Perkel D, Mauk M, Kelly P, Nicoll R, Waxham M. 1989. An essential role for postsynaptic calmodulin and protein kinase activity in long-term potentiation. Nature 340: 554-557.

Malinow R, Malenka R. 2002. AMPA receptor trafficking and synaptic plasticity. Апnи Rev Neurosci 25: 103-126.

Martin S, Grimwood P, Morris R. 2000. Synaptic plasticity and memory: An evaluation of the hypothesis. Annu Rev Neurosci 23: 649-711.

McBain CJ, Fisahn A. 2001. Interneurons unbound. Nat Rev Neurosci 2: $11-23$.

Moulder KL, Jiang X, Taylor AA, Shin W, Gillis KD, Mennerick S. 2007. Vesicle pool heterogeneity at hippocampal glutamate and GABA synapses. J Neurosci 27: 9846-9854.

Nguyen P, Abel T, Kandel E. 1994. Requirement of a critical period of transcription for induction of a late phase of LTP. Science 265: 1104-1107.

O'Dell TJ, Hawkins RD, Kandel ER, Arancio O. 1991a. Tests of the roles of two diffusible substances in long-term potentiation: Evidence for nitric oxide as a possible early retrograde messenger. Proc Natl Acad Sci 88: 11285-11289.

O'Dell TJ, Kandel ER, Grant SG. 1991b. Long-term potentiation in the hippocampus is blocked by tyrosine kinase inhibitors. Nature 353: $558-560$.

Ota KT, Pierre VJ, Ploski JE, Queen K, Schafe GE. 2008. The NO-cGMP-PKG signaling pathway regulates synaptic plasticity and fear memory consolidation in the lateral amygdala via activation of ERK/MAP kinase. Learn Mem 15: 792-805.

Otani S, Marshall C, Tate W, Goddard G, Abraham W. 1989. Maintenance of long-term potentiation in rat dentate gyrus requires protein synthesis but not messenger RNA synthesis immediately post-tetanization. Neuroscience 28: 519-526.

Perry RP, Kelley DE. 1970. Inhibition of RNA synthesis by actinomycin D: Characteristic dose-response of different RNA species. J Cell Physiol 76: 127-139.

Pittenger C, Kandel ER. 2003. In search of general mechanisms for long-lasting plasticity: Aplysia and the hippocampus. Philos Trans R Soc Lond B Biol Sci 358: 757-763.

Raymond C. 2007. LTP forms 1, 2 and 3: Different mechanisms for the "long" in long-term potentiation. Trends Neurosci 30: 167-175.

Raymond C. 2008. Different requirements for action potentials in the induction of different forms of long-term potentiation. J Physiol 586: $1859-1865$

Raymond C, Redman S. 2002. Different calcium sources are narrowly tuned to the induction of different forms of LTP. J Neurophysiol 88: $249-255$.

Raymond C, Redman S. 2006. Spatial segregation of neuronal calcium signals encodes different forms of LTP in rat hippocampus. J Physiol 570: $97-111$.

Raymond C, Thompson V, Tate W, Abraham W. 2000. Metabotropic glutamate receptors trigger homosynaptic protein synthesis to prolong long-term potentiation. J Neurosci 20: 969-976.

Regehr WG, Carey MR, Best AR. 2009. Activity-dependent regulation of synapses by retrograde messengers. Neuron 63: 154-170.
Reymann K, Frey J. 2007. The late maintenance of hippocampal LTP: Requirements, phases, "synaptic tagging," "late-associativity" and implications. Neuropharmacology 52: 24-40.

Sakaba T. 2008. Two $\mathrm{Ca}(2+)$-dependent steps controlling synaptic vesicle fusion and replenishment at the cerebellar basket cell terminal. Neuron 57: $406-419$.

Schuman EM, Madison DV. 1991. A requirement for the intercellular messenger nitric oxide in long-term potentiation. Science 254: $1503-1506$.

Sebeo J, Hsiao K, Bozdagi O, Dumitriu D, Ge Y, Zhou Q, Benson DL. 2009. Requirement for protein synthesis at developing synapses. J Neurosci 29: $9778-9793$.

Shi SH, Hayashi Y, Petralia RS, Zaman SH, Wenthold RJ, Svoboda K, Malinow R. 1999. Rapid spine delivery and redistribution of AMPA receptors after synaptic NMDA receptor activation. Science 284: $1811-1816$.

Shifrin VI, Anderson P. 1999. Trichothecene mycotoxins trigger a ribotoxic stress response that activates c-Jun N-terminal kinase and p38 mitogen-activated protein kinase and induces apoptosis. J Biol Chem 274: $13985-13992$.

Shitaka Y, Matsuki N, Saito H, Katsuki H. 1996. Basic fibroblast growth factor increases functional L-type $\mathrm{Ca} 2+$ channels in fetal rat hippocampal neurons: Implications for neurite morphogenesis in vitro. J Neurosci 16: 6476-6489.

Shors TJ, Matzel LD. 1997. Long-term potentiation: What's learning got to do with it? Behav Brain Sci 20: 597-614; discussion 614-555.

Sokolov M, Rossokhin A, Astrelin A, Frey J, Voronin L. 2002. Quantal analysis suggests strong involvement of presynaptic mechanisms during the initial $3 \mathrm{~h}$ maintenance of long-term potentiation in rat hippocampal CA1 area in vitro. Brain Res 957: 61-75.

Son H, Hawkins RD, Martin K, Kiebler M, Huang PL, Fishman MC, Kandel ER. 1996. Long-term potentiation is reduced in mice that are doubly mutant in endothelial and neuronal nitric oxide synthase. Cell 87: 1015-1023.

Stanton PK, Sarvey JM. 1984. Blockade of long-term potentiation in rat hippocampal CA1 region by inhibitors of protein synthesis. J Neurosci 4: $3080-3088$.

Stanton P, Winterer J, Zhang X, Muller W. 2005. Imaging LTP of presynaptic release of FM1-43 from the rapidly recycling vesicle pool of Schaffer collateral-CA1 synapses in rat hippocampal slices. Eur J Neurosci 22 2451-2461.

Steward O, Levy WB. 1982. Preferential localization of polyribosomes under the base of dendritic spines in granule cells of the dentate gyrus. J Neurosci 2: 284-291.

Steward O, Schuman EM. 2003. Compartmentalized synthesis and degradation of proteins in neurons. Neuron 40: $347-359$.

Sutton MA, Schuman EM. 2005. Local translational control in dendrites and its role in long-term synaptic plasticity. J Neurobiol 64: 116-131.

Sutton MA, Schuman EM. 2006. Dendritic protein synthesis, synaptic plasticity, and memory. Cell 127: 49-58.

Voronin L, Altinbaev R, Bayazitov I, Gasparini S, Kasyanov A, Saviane C, Savtchenko L, Cherubini E. 2004. Postsynaptic depolarisation enhances transmitter release and causes the appearance of responses at "silent" synapses in rat hippocampus. Neuroscience 126: 45-59.

Wiegert JS, Hofmann F, Bading H, Bengtson CP. 2009. A transcription-dependent increase in miniature EPSC frequency accompanies late-phase plasticity in cultured hippocampal neurons. $B M C$ Neurosci 10: 124

Xiong W, Kojic LZ, Zhang L, Prasad SS, Douglas R, Wang Y, Cynader MS 2006. Anisomycin activates p38 MAP kinase to induce LTD in mouse primary visual cortex. Brain Res 1085: 68-76.

Yin HH, Davis MI, Ronesi JA, Lovinger DM. 2006. The role of protein synthesis in striatal long-term depression. J Neurosci 26: 11811-11820.

Yuste R, Bonhoeffer T. 2001. Morphological changes in dendritic spines associated with long-term synaptic plasticity. Annu Rev Neurosci 24: 1071-1089.

Zakharenko S, Zablow L, Siegelbaum S. 2001. Visualization of changes in presynaptic function during long-term synaptic plasticity. Nat Neurosci 4: $711-717$.

Zakharenko S, Patterson S, Dragatsis I, Zeitlin S, Siegelbaum S, Kandel E, Morozov A. 2003. Presynaptic BDNF required for a presynaptic but not postsynaptic component of LTP at hippocampal CA1-CA3 synapses. Neuron 39: 975-990.

Zhang Xh, Poo M-m. 2002. Localized synaptic potentiation by BDNF requires local protein synthesis in the developing axon. Neuron 36: $675-688$.

Zhu PJ, Erdemli G. 1995. Nitric oxide may be a mediator of effects of prolonged but not brief anoxia in CA1 neurons in slices. Neuropharmacology 34: 75-80.

Received July 18, 2011; accepted in revised form July 26, 2011. 


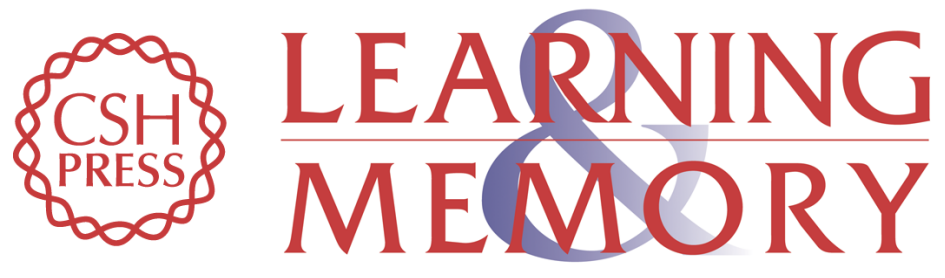

\section{A protein synthesis and nitric oxide-dependent presynaptic enhancement in persistent forms of long-term potentiation}

Victoria P.A. Johnstone and Clarke R. Raymond

Learn. Mem. 2011, 18:

Access the most recent version at doi:10.1101/lm.2245911

References This article cites 89 articles, 26 of which can be accessed free at:

http://learnmem.cshlp.org/content/18/10/625.full.html\#ref-list-1

License

Email Alerting Receive free email alerts when new articles cite this article - sign up in the box at the Service top right corner of the article or click here. 